\title{
Rheumatic Heart Disease in the Young in Iraq
}

\author{
I. R. AL-BAHRANI, M. A. THAMER, M. M. AL-OMERI, AND Y. D. AL-NAAMAN \\ From the Department of Medicine and the Cardio-Thoracic Unit, the Republic Teaching Hospital, University of \\ Baghdad, Baghdad, Iraq
}

Rheumatic heart disease is still the leading cardiac ailment in Iraq. This was the situation in Europe and the United States 25 years ago, but with improvements in the standard of living, better housing, advances in medical services, and education, the picture has changed, and nowadays rheumatic heart disease occupies third place among cardiac disorders after coronary arterial and hypertensive heart diseases (Padmavati, 1958).

In a study at the Republic Teaching Hospital, Baghdad, 48 per cent of patients admitted to the women's ward in congestive heart failure had rheumatic heart disease (Damluji et al., 1964). This is the experience of many observers in other developing countries in Asia and Africa with similar social and economic conditions to Iraq.

In India rheumatic heart disease accounts for 39 per cent of heart diseases (Padmavati, 1962), in Mexico for 41 per cent (Chávez, 1942), and in the Philippines for 42 per cent (Alimurung et al., 1955).

In the past few years we have been impressed by the high incidence of rheumatic heart disease in young patients. The present study was undertaken in order to shed some light on the problem.

\section{Subjects AND METhods}

The study embraces 357 patients with chronic rheumatic valvar lesions seen over the past 3 years at the Cardiac Clinic and the Thoracic Unit of the Republic Teaching Hospital. This hospital has about 900 beds and is attached to the Medical School. It is the major general hospital and thoracic centre in the country.

Our patients come from all parts of the country and have variable social standards. The majority are from the poor working-classes, with a low economic status, which means overcrowding, bad housing, and poor hygienic conditions. Their diet consists mainly of rice, dates, and bread, and is therefore deficient in proteins and vitamins.

Received February 1, 1966.
The patients were evaluated, clinically, by two consultants at the same time, and physical findings were compared with radiological and electrocardiographic examinations in each.

\section{RESULTS}

Incidence of Rheumatic Fever. Of the 357 patients, $167(55 \%)$ gave a history of frank rheumatic fever. The incidence was slightly higher in patients under 16 years than in those who were older, and was higher in female than in male patients.

There was no regional variation in prevalence, for these patients came from different parts of the country where the climate varies from dry warm to damp cold, though the incidence of rheumatic fever and rheumatic heart disease was the same.

Sex Incidence and Age. There were 213 female $(60 \%)$ and 144 male ( $40 \%$ ) patients, with a femaleto-male ratio of $1 \cdot 5: 1$. This incidence has also been noted in other developing countries (Halim and Jacques, 1961), and in the West (White, 1951).

Of the young patients (20 years and less), 84 were female $(62 \%)$ and 55 were male $(38 \%)$ with a female-to-male ratio of 1.5:1. Of the older patients (over 20 years), 129 were female (60\%) and 89 were male $(40 \%)$, with the same sex ratio as in the young (Fig. 1). Of the children (under 16 years of age) 31 were male $(52.5 \%)$ and 28 were female $(47.5 \%)$, a male-to-female ratio of $1 \cdot 1: 1$. This finding differs from other age-groups in that the number of male patients predominated slightly over the female.

Age Incidence. The age distribution in the whole series is shown in Table I. Thus $139(38.9 \%)$ were 20 years or less, and of these $59(16.5 \%)$ were children under the age of 16 years.

Grades of Severity of Lesions. Patients were divided into 4 grades according to the severity of 


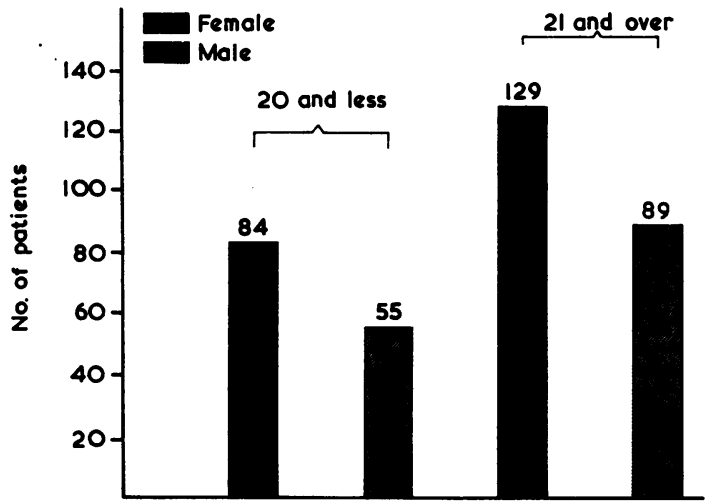

Fig. 1.-Sex distribution in the young (20 years and under), and older (21 years and over) patients with rheumatic heart disease.

their lesions and symptoms. Grade I comprises those with clinical evidence of valvar lesions but with few symptoms. Grade II comprises those with moderate (grade II) symptoms of effort intolerance and with signs of moderate valvar lesions. Grade III comprises those who were severely incapacitated with grade III effort intolerance and early signs of heart failure which responded to treatment. Grade IV comprises those who were totally incapacitated, orthopnœic, and bed-ridden with persistent signs of heart failure despite treatment (Table II).

Over 60 per cent of patients were in grade III or IV, and thus the majority were severely incapacitated when first seeking medical advice. There was no appreciable difference in the degree of severity of lesions in younger and older patients (Fig. 2).

Valve Lesions. The valvar involvement is shown in Table III. More than one valve was involved in 22 young patients $(16.6 \%)$ and 46 older patients $(21 \cdot 1 \%)$. The valvar lesions in both old and young were similar.

Dominant mitral stenosis was present in 77 young patients $(55.4 \%)$ and 133 older patients (61\%), with a female-to-male ratio of $2: 1$ in both age-groups. Out of 210 patients with mitral stenosis, 57 showed a variable degree of tricuspid incompetence (27.1\%).

\section{TABLE I}

AGE INCIDENCE IN 357 PATIENTS WITH RHEUMATIC HEART DISEASE

\begin{tabular}{c|c|c}
\hline Age-group (yr.) & Number of patients & Percentage \\
\cline { 2 - 3 } \cline { 2 - 3 } $1-5$ & 5 & $1 \cdot 4$ \\
$6-10$ & 8 & $2 \cdot 2$ \\
$11-15$ & 46 & $12 \cdot 9$ \\
$16-20$ & 80 & $22 \cdot 4$ \\
Over 20 & 218 & $61 \cdot 1$ \\
\hline
\end{tabular}

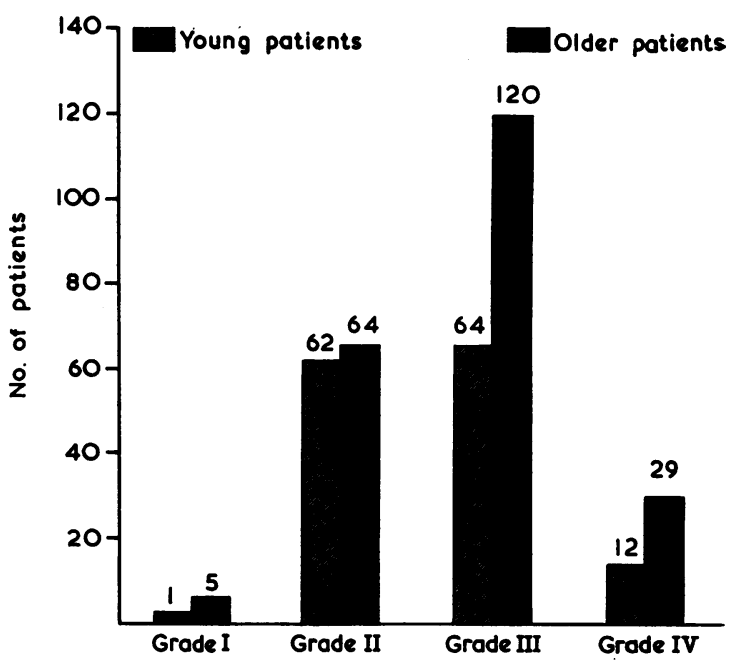

FIG. 2.-Grades of severity of symptoms in the young (under 20 years) and older (21 years and over) patients.

This was thought to be functional in the majority, was attributed to severe right ventricular hypertrophy or right-sided heart failure, and was almost exclusively found in patients having severe mitral stenosis with pulmonary hypertension. In those patients who underwent mitral valvotomy the tricuspid systolic murmur either became softer or disappeared, supporting a functional ætiology. Dominant mitral incompetence was found in 35 young patients $(25 \cdot 2 \%)$ and 23 older patients $(10.6 \%)$, with a female-to-male ratio of $2: 1$ in the younger, and 3:1 in the older patients.

TABLE II

GRADES OF SEVERITY IN 357 PATIENTS WITH RHEUMATIC HEART DISEASE

\begin{tabular}{c|c|c}
\hline Grade & Number of patients & Percentage \\
\cline { 1 - 2 } II & 6 & $1 \cdot 7$ \\
III & 126 & $35 \cdot 3$ \\
IV & 184 & $51 \cdot 6$ \\
$11 \cdot 4$ \\
\hline Total & 41 & 100 \\
\hline
\end{tabular}

TABLE III

COMPARSION OF VALVAR LESIONS BETWEEN 139 YOUNG PATIENTS AND THOSE OF OLDER GROUP WITH RHEUMATIC HEART DISEASE

\begin{tabular}{l|c|c|c|c}
\hline \multicolumn{1}{c|}{ Lesion } & $\begin{array}{c}\text { Age } \\
1-20 \text { years }\end{array}$ & $\begin{array}{c}\text { Percent- } \\
\text { age }\end{array}$ & $\begin{array}{c}\text { Age over } \\
20 \text { years }\end{array}$ & Percentage \\
\cline { 2 - 4 } & 112 & $\begin{aligned} 79 \cdot 9 \\
\text { Mitral }\end{aligned}$ & 156 & $71 \cdot 2$ \\
Aortic & 5 & 3.5 & 16 & 7.4 \\
More than one valve & 22 & 16.6 & 46 & 21.4 \\
\hline Total & 139 & 100 & 218 & 100 \\
\hline
\end{tabular}


TABLE IV

DISTRIBUTION OF VALVAR LESIONS IN THE YOUNGER AND OLDER AGE-GROUPS IN BOTH SEXES

\begin{tabular}{|c|c|c|c|c|c|c|c|c|c|c|}
\hline \multirow[b]{2}{*}{ Lesion } & \multicolumn{2}{|c|}{ Male } & \multicolumn{2}{|c|}{ Female } & \multirow[b]{2}{*}{ Total } & \multirow[b]{2}{*}{ Percentage } & \multicolumn{2}{|c|}{ Over 20} & \multirow[b]{2}{*}{ Total } & \multirow[b]{2}{*}{ Percentage } \\
\hline & $1-10$ years & $11-20$ years & $1-10$ years & $11-20$ years & & & Male & Female & & \\
\hline $\begin{array}{l}\text { Mitral stenosis } \\
\text { Mitral incompetence } \\
\text { Aortic stenosis } \\
\text { Aortic incompetence } \\
\text { More than one valve in- } \\
\text { volved }\end{array}$ & $\begin{array}{l}0 \\
3 \\
0 \\
0 \\
1\end{array}$ & $\begin{array}{r}29 \\
9 \\
0 \\
5 \\
\\
10\end{array}$ & $\begin{array}{l}0 \\
9 \\
0 \\
0 \\
0\end{array}$ & $\begin{array}{r}48 \\
14 \\
0 \\
0 \\
11\end{array}$ & $\begin{array}{r}77 \\
35 \\
0 \\
5 \\
22\end{array}$ & $\begin{array}{c}55 \cdot 4 \\
25 \cdot 2 \\
0 \\
3 \cdot 6 \\
15 \cdot 8\end{array}$ & $\begin{array}{r}45 \\
6 \\
4 \\
8 \\
\\
26\end{array}$ & $\begin{array}{r}88 \\
17 \\
3 \\
1 \\
20\end{array}$ & $\begin{array}{r}135 \\
23 \\
7 \\
9 \\
46\end{array}$ & $\begin{array}{r}61 \\
10 \cdot 6 \\
3 \cdot 2 \\
4 \cdot 1 \\
21 \cdot 1\end{array}$ \\
\hline Total & 4 & 53 & 9 & 73 & 139 & 100 & 89 & 129 & 218 & 100 \\
\hline
\end{tabular}

TABLE V

COMPARISON BETWEEN VALVE LESION IN 59 CHILDREN (UNDER 16 YEARS) WITH THAT IN 218 ADULTS (OVER 20 YEARS)

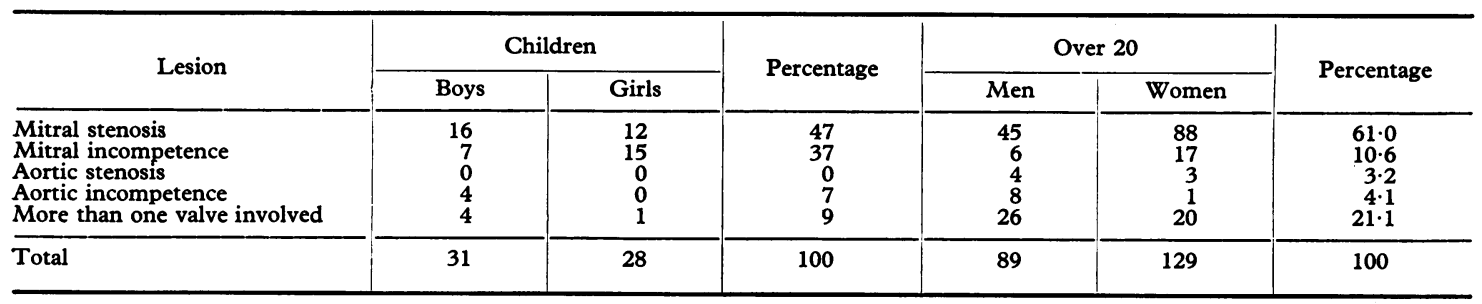

Aortic stenosis was absent in the younger group but was present in 7 older patients $(3 \cdot 2 \%)$, with a nearly equal sex incidence. Aortic incompetence, on the other hand, was found in 5 young patients (3.6\%) and in 9 older patients $(4.1 \%)$ with a maleto-female ratio of $5: 1$ in the younger, and 8:1 in the older patients (Table IV).

In children (under 16 years) the picture was slightly different, 28 cases having dominant mitral stenosis $(47 \%)$ with a male-to-female ratio of $4: 3$. Dominant mitral incompetence was found in 22 patients $(37 \%)$ with a female-to-male ratio of $2: 1$. Aortic stenosis was absent in this age-group, but aortic incompetence was present in 4 (7\%) (Table V). The most interesting finding was that all patients under the age of 11 years with mitral valve disease had dominant mitral incompetence.

\section{Discussion}

The incidence of rheumatic heart disease in young patients has been high in this study, accounting for over one-third $(39 \%)$ of our patients with this disease. This figure is similar to figures from other developing countries in Asia and Africa. In a similar study in the Sudan, 116 of 243 patients with rheumatic heart disease were under 20 years of age $(45.6 \%)$ (Halim and Jacques, 1961) (Table VI). The valvar lesions in the same study were closely similar to those of the present series. In another study in India, of 754 cases of rheumatic heart disease, 171 were under 20 (23\%) (Roy et al., 1963).

In the west the picture is different, for the incidence of rheumatic heart disease in young patients does not exceed 5 per cent, and in a study in Den-

TABLE VI

COMPARISON OF AGES OF PRESENT SERIES OF 357 PATIENTS WITH RHEUMATIC HEART DISEASE WITH THOSE IN THE SERIES OF HALIM AND JACQUES (1961) OF 243 CASES OF RHEUMATIC HEART DISEASE IN THE SUDAN

\begin{tabular}{|c|c|c|c|c|c|}
\hline \multicolumn{3}{|c|}{$\begin{array}{l}243 \text { cases of rheumatic heart disease } \\
\text { (Halim and Jacques, 1961) }\end{array}$} & \multicolumn{3}{|c|}{$\begin{array}{l}357 \text { cases of rheumatic heart disease } \\
\text { (present series) }\end{array}$} \\
\hline Age (yr.) & Cases & Percentage & Age (yr.) & Cases & Percentage \\
\hline $\begin{array}{c}0-9 \\
10-19 \\
\text { Over } 20\end{array}$ & $\begin{array}{r}23 \\
93 \\
127\end{array}$ & $\begin{array}{r}9 \cdot 8 \\
35 \cdot 8 \\
54 \cdot 4\end{array}$ & $\begin{array}{l}1-10 \\
11-20 \\
\text { Over } 20\end{array}$ & $\begin{array}{r}13 \\
126 \\
218\end{array}$ & $\begin{array}{r}3 \cdot 6 \\
35 \cdot 3 \\
61 \cdot 1\end{array}$ \\
\hline Total & 243 & 100 & Total & 357 & 100 \\
\hline
\end{tabular}


mark of 271 cases of mitral stenosis only 8 were under 20 years $(3 \%$ ) (Olesen, 1962). The reasons for the higher incidence of rheumatic heart disease in young patients in developing countries are not clear, but several factors may contribute and these will be discussed later.

The sex distribution in our series shows a femaleto-male preponderance with a ratio of $1.5: 1$ in both younger and older age-groups, as in other studies (Halim and Jacques, 1961; White, 1951). In children the sex dominance is slightly in favour of males with ratio of $1 \cdot 1: 1$.

The majority of our patients were severely incapacitated by their disease and over 60 per cent were in grade III or IV when first seeking medical advice, while no major differences were found in various age-groups. The mitral valve was involved in 268 cases $(75.1 \%)$, the aortic valve in 21 cases $(6 \%)$, and more than one valve in 68 cases $(18.9 \%)$.

Mitral stenosis was found in 210 cases $(60 \%)$ with similar percentage in both younger and older agegroups and a female-to-male ratio of nearly $2: 1$ in both age-groups. In children mitral stenosis was more frequent in boys than in girls in a ratio of $4: 3$.

In another study (Al-Naaman et al., 1966) we found that severe degrees of mitral stenosis were seen in patients under the age of 20 and even under 16 years. Mitral valvotomy in these patients almost invariably revealed a mitral valve orifice of less than $1 \mathrm{~cm}$., with frequent thickening and often calcification. About 40 per cent of patients who came to mitral valvotomy were aged 20 years or less. This again is similar to the experience of many workers in other developing countries in Asia and Africa (Cherian et al., 1964; H. Sayed, 1965, personal communication; Borman et al., 1961). This contrasts sharply with the findings in the Western hemisphere, where young patients undergoing mitral valvotomy do not account for more than 5 per cent of total valvotomies (Goodwin et al., 1955; Bailey and Bolton, 1956; Glover, 1959).

Mitral incompetence was found in 58 of our patients $(15 \%)$ with a female sex dominance in all age-groups and a female-to-male ratio of $2: 1$, but the interesting finding was that all patients under the age of 11 years had dominant mitral incompetence. These patients were followed for from 6 months to 3 years with no change in the physical signs or in the character of the murmur, and we think that early involvement of the mitral valve by the rheumatic process had led to severe destruction and deformity of the valve and thus to incompetence. But myocardial involvement by the rheumatic process, which might lead to dilatation of the mitral ring secondary to left ventricular hypertrophy and dilatation, cannot be excluded.

Aortic stenosis was absent in young patients and was present in 7 older patients with equal sex incidence. By contrast aortic incompetence was present in 14 patients $(4 \%)$ with a dominantly male incidence and a ratio of 8:1 in older and 5:1 in younger patients.

The reason for the high incidence of rheumatic heart disease in young patients in Iraq is not fully understood, but we think that several factors may contribute, the most important being social and economic. Poor hygienic conditions, inadequate medical treatment due to financial difficulties, and ignorance are factors. The unsatisfactory treatment of rheumatic fever and streptococcal sore throat, and sometimes the failure of diagnosis of subclinical forms, are also important. Finally, the follow-up of patients with rheumatic fever is often inadequate, in that patients with such a history often fail to carry out adequate prophylaxis. Poor nutrition may play a part also.

We do not think that climate has anything to do with the high incidence of rheumatic heart disease, for patients in this series came from various parts of Iraq where the climate varies from cold and damp to hot and dry.

A better standard of living, housing, education, and improved medical services will probably lead to a fall in the incidence of rheumatic heart disease as a whole, and in the young in particular in developing countries.

\section{SUMMARY}

Rheumatic heart disease is still the leading heart disease in Iraq, with a high incidence in young patients, and of 357 patients studied 39 per cent were under 20 years of age.

The sex incidence in this series was 213 female $(60 \%)$ and 144 male (40\%) patients with a femaleto-male ratio of 1.5:1. In children (under 16) boys slightly predominated, however.

The majority of patients were severely incapacitated by the disease when first seeking medical advice.

Mitral stenosis was found in 210 patients with a female-to-male ratio of $2: 1$ in both younger and older patients. In children the sex incidence was in favour of boys with a ratio of 4:3. Mitral incompetence was found in 35 young patients (under 20 years) $(25.2 \%$ ), and 23 older (over 20 years) patients $(10.6 \%)$ with the same sex incidence as in mitral stenosis. Mitral incompetence was the main valvar lesion in all patients under the age of 11 years: the possible reasons for this finding are discussed. 
Aortic stenosis was absent in young patients and present in 7 older patients with equal sex incidence. Aortic incompetence on the other hand was present in 5 young patients $(3.6 \%)$ and 9 older patients (4.1\%) with a male-to-female ratio of 5:1 in younger and $8: 1$ in older patients.

Comparing the present figures with those from other developing countries in Asia and Africa revealed a close similarity, but comparing them with those in the Western hemisphere, where mitral valve disease in children is less common, there were considerable differences.

The reason for the high incidence of rheumatic heart disease in young patients in Iraq is not fully known, but poor hygienic conditions, overcrowding, bad housing, inadequate medical treatment and prophylaxis, and possibly a nutritional factor may all contribute.

We wish to express our thanks to Professor John Goodwin for his comments and kind advice.

\section{REFERENCES}

Alimurung, M. M., Herrera, F., Guytingco, A., and Cruz, P. M. (1955). Heart disease in the Philippines. A seven-year (1947-1953) postwar survey of four Manila general hospitals. Amer. Heart f., 50, 293.

Bailey, C. P., and Bolton, H. E. (1956). Criteria for and results of surgery for mitral stenosis. N.Y. med. J., 56, 825 .
Borman, J. B., Stern, S., Shapira, T., Milwidsky, H., and Braun, K. (1961). Mitral valvotomy in children. Amer. Heart F., 61, 763.

Chávez, I. (1942). The incidence of heart disease in Mexico. A study of 2,400 cases of organic heart disease. Amer. Heart $\mathcal{F}$., 24, 88.

Cherian, G., Vytilingam, K. I., Sukumar, I. P., and Gopinath, N. (1964). Mitral valvotomy in young patients. Brit. Heart f., 26, 157.

Damluji, S. F., Al-Saffar, G., Thamer, M. A., and Mary, A. S. (1964). Congestive heart failure in women in Iraq. Bull. Wld Hlth Org., 31, 337.

Glover, R. P. (1959). Mitral surgery in a young girl. Amer. f. Cardiol., 4, 132.

Goodwin, J. F., Hunter, J. D., Cleland, W. P., Davies, L. G., and Steiner, R. E. (1955). Mitral valve disease and mitral valvotomy. Brit. med. F., 2, 573.

Halim, A. M., and Jacques, J. E. (1961). Rheumatic heart disease in the Sudan. Brit. Heart F., 23, 383.

Al-Naaman, Y. D., Thamer, M. A., Al-Bahrani, I. R., and Al-Omeri, M. M. (1966). A critical analysis of mitral commissurotomy in children and the young. International Surgery, Vol. 45, No. 5, May 1966.

Olesen, K. H. (1962). The natural history of 271 patients with mitral stenosis under medical treatment. Brit. Heart F., 24, 349.

Padmavati, S. (1958). A five-year survey of heart disease in Delhi. Indian Heart F., 10, 33.

- (1962). Epidemiology of cardiovascular disease in India. I. Rheumatic heart disease. Circulation, 25, 703.

Roy, S. B., Bhatia, M. L., Lazaro, E. J., and Ramalingaswami, V. (1963). Juvenile mitral stenosis in India. Lancet, 2, 1193.

White, P. D. (1951). Heart Disease, 4th ed. Macmillan, New York. 